\title{
ESTRATÉGIAS DE ENSINO: Jogos Matemáticos
}

\author{
$\underline{\text { Arlete Cherobini }}$ \\ Faculdade La Salle \\ 78455- 000, Lucas do Rio Verde, MT \\ E-mail: arlete@faculdadelasalle.edu.br
}

\begin{abstract}
Resumo: Através de pesquisas e estudos busca-se mostrar a importância dos jogos para aprendizagem, visto que são componentes essenciais na vida dos educandos. Os jogos como fonte de desenvolvimento contribuem para a criatividade, o crescimento intelectual, social e emocional $e$ devem ser encarados com muita seriedade, pois são mais do que um passa tempo, são elementos indispensáveis para a expressão da personalidade e para a integração na sociedade. A prática de jogos auxilia o professor a complementar suas aulas, fazendo com que os educandos se interessem pelas mesmas, estimulando o raciocínio lógico matemático proporcionando a ele uma forma divertida e prazerosa de aprender Matemática. A utilização de jogos Matemáticos é um dos métodos, onde se aprende brincando, ao mesmo tempo em que são desenvolvidos os conteúdos matemáticos trabalha-se também de certa forma o raciocínio lógico. Além disto, o professor tem a oportunidade de criar um ambiente na sala de aula em que os recursos da comunicação estejam presentes, propiciando momentos como: apresentar, trocar experiências, discussões, interações entre alunos e professor, com vistas a tornar as aulas mais interessantes e desafiadoras.
\end{abstract}

Palavras chave: Jogos, aprendizagem, desenvolvimento, habilidades.

\section{Introdução}

O presente artigo busca mostrar a importância dos jogos para aprendizagem, visto que os jogos são componentes essenciais na vida dos nossos educandos. Os jogos como fonte de desenvolvimento contribuem para a criatividade, crescimento intelectual, social e emocional do educando.

Os jogos não devem ser vistos como passa tempo, pois são elementos indispensáveis à expressão da personalidade e a integração na sociedade. Seguramente traduzem a autêntica ação sócia pedagógica da educação. É através deles que os educandos adquirem, além do aspecto psicomotor, relacionamento social e afetivo, indispensáveis na formação da pessoa humana.

$\mathrm{O}$ uso de jogos auxilia o professor a complementar suas aulas, fazendo com que os alunos se interessem pelas mesmas, estimulando o raciocínio lógico matemático, capacitando o aluno para elaboração de novas estratégias, auxiliando no desenvolvimento da agilidade mental, proporcionando a ele uma forma divertida e prazerosa de aprender Matemática.

O objetivo deste trabalho é apresentar como os jogos em sua universalidade, dentro de uma proposta pedagógica estimulam o desenvolvimento das competências necessárias em cada fase de aprendizagem. Pois, busca desenvolver no aluno a autoconfiança, organização, concentração, atenção, raciocínio lógico e rápido, despertar o interesse, gosto pelo jogo, muitas vezes criando suas próprias regras e o senso cooperativo entre os alunos, a participação de todos dentro de uma atividade, exercer os jogos como forma de convívio agradável e mostrar que o jogo ensina a conviver uns com os outros ao invés de uns contra os outros. 
O jogo é uma ação, desta ação faz parte o sujeito que através do jogo pode conhecer-se melhor, estabelecendo estratégias, desenvolvendo suas potencialidades, competências, desencadeando a construção de conhecimentos. É um componente essencial na vida do educando, ele proporciona vida a sua imaginação, desenvolve suas aptidões, tanto físicas como intelectuais.

\section{Entendendo o Jogo Pedagógico}

De acordo com as Diretrizes para o Ensino da Matemática (MEC, 2006), um dos desafios do ensino da Matemática é a abordagem de conteúdos para resolução de problemas. Trata-se de uma metodologia pela qual o estudante tem oportunidade de aplicar conhecimentos matemáticos adquiridos em novas situações, de modo a resolver a questão proposta.

Nos últimos 30 anos, tanto no Brasil como em outros países, pesquisas educacionais realizadas mostraram que os processos envolvidos no ensino e na aprendizagem são muito mais complexos do que se acredita e concluiu-se que a matemática está ligada à compreensão e não apenas conteúdos decorados.

Nos PCNs (1998, p. 46), lê-se que:

Os jogos constituem uma forma interessante de propor problemas, pois permitem que estes sejam apresentados de modo atrativo e favorecem a criatividade na elaboração de estratégias de resolução e busca de soluções. Propicia a simulação de situações-problema que exigem soluções vivas e imediatas, o que estimula o planejamento das ações; possibilitam a construção de uma atitude positiva perante os erros, uma vez que as situações sucedem-se rapidamente e podem ser corrigidas de forma natural, no decorrer da ação, sem deixar marcas negativas.

O jogo pedagógico pode ser entendido como um instrumento utilizado pelo professor como facilitador no processo de aprendizagem do aluno, desenvolvendo no mesmo, a capacidade de pensar, refletir, analisar, criar, além do desenvolvimento dos processos de autonomia e socialização, que acredito serem os aspectos mais significativos proporcionados pelo jogo.

$\mathrm{Na}$ educação, como um todo, devemos ter objetivos claros a serem atingidos e nossas ações devem converter para tais objetivos. O objetivo é o caminho da educação representam a reorganização de conhecimentos que partam do interesse e da necessidade do educando, incentivando tudo que possa maximizar o processo de construção de conhecimento.

O jogo pode desencadear vários processos de construção de conhecimentos de uma maneira mais atrativa e desafiadora. Se o jogo é útil no ensino como um todo, porque não desenvolvê-lo no ensino da Matemática, que é considerado por muitos, como de difícil compreensão e de exercícios meramente repetitivos, que não estimula o aluno a investigar, a raciocinar, e principalmente, criar suas estratégias.

Os jogos no ensino da Matemática não servem apenas para motivar os alunos, mas, também para ensinar conceitos e construir conhecimentos. Os jogos propiciam condições para que o ensino da Matemática ocorra dentro de um processo de maior participação do aluno, pois este é motivo a pensar, 
descobrir, reinventar e não só receber informações prontas. Assim, o jogo pode fixar conteúdos, desenvolvendo o senso crítico, estimular o raciocínio, oportunizando ao aluno a apropriação de novos conhecimentos.

Os autores Smole, Diniz e Milani, (2007) lembram-nos que as habilidades são desenvolvidas nos alunos durante a ação de jogar, pois é nesses momentos e que o aluno torna protagonista de sua ação e, portanto faz uso de estratégias diversas para encontrar a resolução do problema apresentado, entre as estratégias o conhecimento matemático e de suma importância. Durante a ação de jogar, o qual oferece prazer, ainda há a aquisição da aprendizagem da matemática.

É fundamental partir do pressuposto de que o aprendiz busca o "escutar" da experiência do professor, portanto deixa-los descobrir novas experiências faz parte do aprendizado, os jogos oferecem inúmeras possibilidades questionamentos, de erros e de acertos.

Segundo Kamii (1995, p.172) “a interação social implícita nos jogos de matemática, fornece uma alternativa para o professor como recurso do encontro de respostas certas", ainda, que quando as crianças discutem quais respostas estão certas, elas se tornam fontes da verdade, desenvolvem confiança para descobrir coisas novas, defendem ou corrigem seus próprios processos de pensar em vez de esperar pelas respostas.

Ainda de acordo com Borin (2004, p. 8) realça que:

\begin{abstract}
A atividade de jogar, se bem orientada, tem papel importante no desenvolvimento de habilidades de raciocínio como organização, atenção e concentração, tão necessárias para o aprendizado, em especial da Matemática, e para a resolução de problemas em geral. [...] Também, no jogo, identificamos o desenvolvimento da linguagem, criatividade e raciocínio dedutivo, exigidos na escolha de uma jogada e na argumentação necessária durante a troca de informações.
\end{abstract}

Vimos que à medida que os alunos vão jogando, estes percebem que o jogo não é apenas um passa tempo organizado com regras a serem vencidas, mas que deve ser encarado como um desafio, que exige reflexões das tais regras do jogo, e para tanto é necessário que o jogador exerça as competências necessárias, desenvolvendo, portanto as habilidades relacionadas aos aspectos desse jogo com determinados conceitos matemáticos.

Para tanto vale ressaltar, que o jogo deve ter as regras pré-estabelecidas e estas não podem ser alteradas durante uma partida. Quando os participantes perceberem que há necessidade de fazer alterações nas regras, estas devem ser acordadas entre uma partida e outra, pois as negociações fazem parte do aprendizado significativo do aluno.

No entanto Starepravo (1999) preconiza que o professor quando vai preparar suas aulas e nelas faz uso de jogos é preciso fazer escolhas das técnicas que explore integralmente da virtualidade do jogo, e, principalmente nos lembra de que a análise das metodologias conveniente ao objetivo em que pretende alcançar.

Exemplifica Starepravo (1999) tais como: 
[...] a melhor maneira de organizar os grupos e a seleção de jogos que sejam adequados ao conteúdo que se pretende trabalhar. O trabalho com jogos requer do professor certas atitudes que o levem a considerar como uma atividade a ser realizada durante todo o ano letivo, e não de modo esporádico, relacionando o jogo como uma estratégia aliada à construção do conhecimento, devendo planejar cuidadosamente sua execução (STAREPRAVO apud BARBOSA e CARVALHO, 2009, p.07).

Nesse caso, acredito ser importante lembrar que o professor deve orientar os seus alunos a anotação descritiva das ações sequências feita na jogadas para que possa analisar futuramente suas manobras e, então, a visualização dos erros e acertos.

Assim, os registros matemáticos têm um papel relevante na aprendizagem, pois permitem que o aluno relate o que aprendeu no momento do jogo e passe aos demais essas idéias. Escrever pode ajudá-lo a aprimorar suas percepções e levá-lo a uma reflexão acerca dos conhecimentos adquiridos. "Temos observado que os registros sobre matemática ajudam a aprendizagem dos alunos de muitas formas, encorajando a reflexão, clareando as idéias e agindo como um catalisador para as discussões em grupo" (SMOLE; DINIZ; MILANI, 2007, p.12).

Ainda de acordo com os autores os mesmos sugerem que o professor utilize o mesmo jogo diversas vezes para que o aluno fixe a regras do jogo, ainda que, o professor proporcione a leitura, incentive o entendimento, e principalmente, oriente a escrita das regras e das estratégias utilizadas. E finalmente que o professor estimule a ação criadora em novos jogos.

Neste sentido identifica-se que a presença do jogo estimula o desenvolvimento cognitivo, dentre outros: a raciocinar visando uma meta final; organização com uma determinante concreta; projetar e planejar ações futuras e apoderar de tomadas de decisões nas resoluções de problemas que surjam.

Vale ressaltar que, através da utilização de jogos na sala de aula, estes objetivos poderão ser atingidos por meio de uma atividade que gera prazer e alegria, sendo um desafio constante para o educando. O jogo torna-se um verdadeiro fascínio, desencadeando numa busca permanente da construção de conhecimento.

\section{Considerações Finais}

Ao concluir o presente artigo, verificou-se a importância do jogo para aprendizagem, pois ele não tem somente valor único, é um instrumento que possibilita um desenvolvimento da aprendizagem, indispensável na formação do educando. Além de ajudar o educando a adquirir conhecimento e habilidades, o ato de jogar auxilia a lidar com seus sentimentos intensos de amor e ódio, medo e tristeza, em situações algo distanciado do ponto de origem desses sentimentos.

Os jogos devem exigir que o educando mudasse constantemente de uma atividade para outra, pois quase sempre as emoções envolvidas são também diferentes. $\mathrm{O}$ educando precisa, então ter em mente a ideia do jogo como um todo, e assim poder manter suas emoções controladas. Tudo isto 
representa uma conquista notável. Na medida em que os jogos lhe satisfazem o desejo de buscar, certa dose de risco e aventura, com a certeza de estar em segurança, ajuda a viverem alguns dos perigos reais do mundo externo, e sua autoconfiança aumenta.

Considerando a importância do jogo no desenvolvimento físico e afetivo do educando, somos impelidos a refletir quanto à necessidade de uma melhor conscientização dos professores.

Se há interesse por parte dos professores que o educando aprenda, deverá haver interesse de como este processo se efetue, para que possamos aprimorar os meios a serem utilizados para uma ampliação de uma relação significativa entre conteúdos programáticos e sua aplicabilidade concreta, pois sabemos que, embora o aluno tenha capacidade de abstração, o concreto favorece-lhe mais na sua compreensão global do que executa. A funcionalidade da ação deve ser sentida intensamente e desenvolvida como um todo.

\section{Referências}

[1] BARBOSA, Sandra Lucia Piola. CARVAlHO, Túlio Oliveira de. Jogos Matemáticos como Metodologia de Ensino Aprendizagem das Operações com Números Inteiros. Programa de Desenvolvimento da Educação. Londrina, 2009 disponível: http://www.diaadiaeducacao.pr.gov.br/portals/pde/arquivos/1948-8.pdf: acesso em: 01/07/2003.

[3] BORIN, J. Jogos e resolução de problemas: uma estratégia para as aulas de matemática. 3. ed. São Paulo: IME/USP, 2004.

[4] GRANDO, R. C. O Jogo e suas Possibilidades Metodológicas no Processo EnsinoAprendizagem da Matemática, 1995. Dissertação (Mestrado em Educação, subárea: Matemática). UNICAMP-Campinas.

[3] KAMII, Constance; LIVINGSTON, Sally Jones. Desvendando aritmética. Implicações da Teoria de Piaget. Papirus 1995.

[3] KAMII, Constance; JOSEPH, Linda Leslie. Aritmética: novas perspectivas. Implicações da Teoria de Piaget. $4^{\mathrm{a}}$ edição. Papirus 1995.

[3] KISHIMOTO, T, M. O Jogo e a Educação Infantil. São Paulo: Livraria Pioneira Editora, 1994.

[3] MEC. Parâmetros Curriculares Nacionais ( $1^{\text {a }}$ a $4^{\text {a }}$ série): matemática. Secretaria de Educação. Educação Fundamental. Brasília: MEC/ SEF, 1997.

[3] __ Diretrizes Curriculares Para a Educação Básica da Disciplina de Matemática. Secretaria de Estado de Educação do Paraná, 2008.

[3] MOURA, M. O. O Jogo e a construção do conhecimento matemático. São Paulo: FDE, 1992b. (Série Ideias 10).

[3] SMOLE, K.S.; DINIZ, M.I.; MILANI, E. Jogos de matemática do $6^{\circ}$ ao $9^{\circ}$ ano. Cadernos do Mathema. Porto Alegre: Artmed 2007.

[3] STAREPRAVO, A.R. Jogos, desafios e descobertas: o jogo e a matemática no ensino fundamental - séries iniciais. Curitiba: Renascer, 1999. 